\title{
Papers
}

\section{Selective chromosome analysis in couples with two or more miscarriages: case-control study}

\author{
Maureen T M Franssen, Johanna C Korevaar, Nico J Leschot, Patrick M M Bossuyt, Alida C Knegt, Klasien B J \\ Gerssen-Schoorl, Cokkie H Wouters, Kerstin B M Hansson, Ron Hochstenbach, Kamlesh Madan, Fulco van der Veen, \\ Mariette Goddijn
}

\begin{abstract}
Objective To identify additional factors, such as maternal age or factors related to previous reproductive outcome or family history, and the corresponding probability of carrying a chromosome abnormality in couples with two or more miscarriages.

Design Nested case-control study.

Setting Six centres for clinical genetics in the Netherlands. Participants Couples referred for chromosome analysis after two or more miscarriages in 1992-2000; 279 carrier couples were marked as cases, and 428 non-carrier couples served as controls.
\end{abstract}

Main outcome measures Independent factors influencing the probability of carrier status and the corresponding probability of carrier status.

Results Four factors influencing the probability of carrier status could be identified: maternal age at second miscarriage, a history of three or more miscarriages, a history of two or more miscarriages in a brother or sister of either partner, and a history of two or more miscarriages in the parents of either partner. The calculated probability of carrier status in couples referred for chromosome analysis after two or more miscarriages varied between $0.5 \%$ and $10.2 \%$.

Conclusions The probability of carrier status in couples with two or more miscarriages is modified by additional factors. Selective chromosome analysis would result in a more appropriate referral policy, could decrease the annual number of chromosome analyses, and could therefore lower the costs.

\section{Introduction}

Couples who have had two or more miscarriages are at increased risk of either of the partners carrying a structural chromosome abnormality. The incidence of carrier status increases from approximately $0.7 \%$ in the general population to $2.2 \%$ after one miscarriage, $4.8 \%$ after two miscarriages, and 5.2\% after three miscarriages. ${ }^{12}$ If one of the partners carries a structural chromosome abnormality, products of conception can have a normal karyotype, the same karyotype as the carrier parent, or an unbalanced karyotype. The last of these can lead to miscarriage, stillbirth, or the birth of a child with major congenital impairments. Prenatal diagnosis is therefore offered to carrier couples in subsequent pregnancies. No consensus exists between current guidelines for the management of recurrent miscarriage on whether chromosome analysis should be offered after two or three miscarriages. For example, the Royal College of
Obstetricians and Gynaecologists recommends chromosome analysis after three miscarriages, whereas the American College of Obstetricians and Gynecologists and the Dutch Society of Obstetrics and Gynaecology recommend chromosome analysis after two miscarriages. ${ }^{3-5}$

These guidelines are based on the fact that the probability of carrier status is increased after two or three miscarriages. Whether this probability is also modified by maternal age or by factors related to previous reproductive outcome or family history is not known. If it is, the possibility of withholding chromosome analysis from couples with a low probability of carrier status could be considered. We aimed to identify additional factors influencing the probability of carrier status in couples with two or more miscarriages and to calculate the associated probability of carrier status for every combination of these factors.

\section{Methods}

\section{Patients}

We used the databases of six centres for clinical genetics in the Netherlands to identify all couples referred for chromosome analysis after two or more miscarriages between 1 January 1992 and 1 January 2001. We marked as cases all couples in which one of the partners was found to be a carrier of a structural chromosome abnormality. As controls, we selected a random subset of two non-carrier couples for each carrier couple by identifying the last couple tested before the carrier couple and the first couple tested after the carrier couple in each centre. We recorded karyotypes according to the recommendations of the International Standing Committee on Human Cytogenetic Nomenclature. ${ }^{6}$ We included only couples with at least two miscarriages with a gestational age up to 20 weeks and verified by a pregnancy test or ultrasonography. We excluded patients with other genetic diseases likely to cause fetal chromosome abnormalities and those with a language barrier.

\section{Data collection}

We contacted eligible couples by mail and invited them to participate in the study. After obtaining written informed consent, we examined the medical records of the relevant department of clinical genetics, and both partners filled out a questionnaire. We collected additional information by using telephone interviews and from medical records of the referring physician or midwife. The data collection was focused on the parental characteristics at the time of chromosome analysis, 


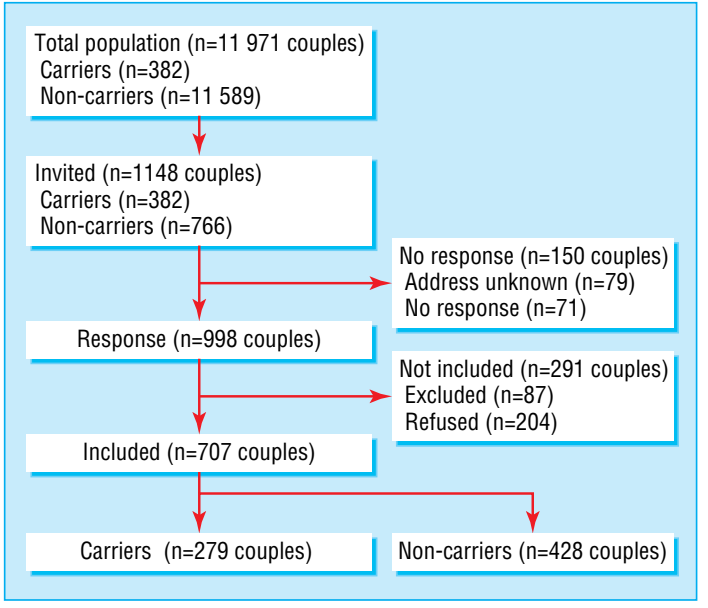

Fig 1 Flowchart of trial population and inclusion

including general history, maternal age, obstetric history, and family history.

\section{Statistical analysis}

We used logistic regression analysis to identify factors influencing the probability of carrier status and to calculate the corresponding probability of carrier status. We divided variables into five subgroups: general history; maternal age at chromosome analysis, at first miscarriage, and at second miscarriage; number of miscarriages; obstetric history; and family history. We used splines analysis to determine whether a linear relation existed between continuous variables and the probability of carrier status. In the case of a non-linear relation, we transformed continuous variables into categorical variables on the basis of the results of the splines analysis. We then did univariate logistic regression analysis with all variables. We retained variables with $\mathrm{P} \leq 0.2$ in the univariate analysis for subsequent steps.

In the multivariate logistic regression analysis, we added variables to the model by subgroup. We retained only variables with $\mathrm{P} \leq 0.1$ in the model. If two variables were highly correlated, we retained the one leading to the best improvement of the model. To determine whether the sequence of the subgroups influenced the final model, we repeated the analysis using different selection orders and comparing the results from each model.

At selection, we matched the non-carrier couples to the carrier couples within each genetic centre and by time of chromosome analysis. To exclude a bias introduced by these potential confounders, we compared the results of logistic regression analysis with the results of conditional regression analysis.

As this was a nested case-control study, we had to adjust the model for the relative proportions of cases and controls in the total population of couples referred for chromosome analysis after two or more miscarriages. ${ }^{7}$ We then calculated the probability of carrier status from the final model for every combination of variables. We used SPSS 11.5.1 for all analyses.

\section{Results}

Between 1 January 1992 and 1 January 2001, 11971 couples had been referred to the participating centres for chromosome analysis after two or more miscarriages. We invited 1148 couples to participate in the study-all 382 carrier couples and 766 noncarrier couples. We included $62 \%$ of the invited couples-279 (73\%) carrier couples and 428 (56\%) non-carrier couples (fig 1).
Table 1 Baseline characteristics of couples at time of chromosome analysis. Values are mean (range) unless stated otherwise

\begin{tabular}{|c|c|c|c|}
\hline Characteristic & Carriers ( $n=279$ ) & Non-carriers $(n=428)$ & $P$ value \\
\hline $\begin{array}{l}\text { Chromosome analysis after } \\
\text { two miscarriages-No } \\
(\%)\end{array}$ & $108(39)$ & $212(50)$ & $0.010^{*}$ \\
\hline $\begin{array}{l}\text { Chromosome analysis after } \\
\text { three miscarriages-No } \\
(\%)\end{array}$ & $112(40)$ & $153(36)$ & \\
\hline $\begin{array}{l}\text { Chromosome analysis after } \\
\text { four or more } \\
\text { miscarriages-No (\%) }\end{array}$ & $59(21)$ & $63(14)$ & \\
\hline $\begin{array}{l}\text { Maternal age at time of } \\
\text { chromosome analysis } \\
\text { (years) }\end{array}$ & $31.8(20-43)$ & $32.7(19-47)$ & $0.012 \dagger$ \\
\hline $\begin{array}{l}\text { Maternal age at first } \\
\text { miscarriage (years) }\end{array}$ & $29.0(17.3-41.3)$ & $30.2(16.0-47.7)$ & $0.001 \dagger$ \\
\hline $\begin{array}{l}\text { Maternal age at second } \\
\text { miscarriage (years) }\end{array}$ & $30.5(19.0-41.5)$ & $31.6(17.7-48.1)$ & $0.002 \dagger$ \\
\hline $\begin{array}{c}\text { No of miscarriages before } \\
\text { chromosome analysis }\end{array}$ & $3.0(2-10)$ & $2.8(2-12)$ & $0.002 \dagger$ \\
\hline $\begin{array}{l}\text { Gestational age of } \\
\text { miscarriages (weeks) }\end{array}$ & $9.4(5.2-15.3)$ & $9.4(4.8-15.0)$ & $0.925 \dagger$ \\
\hline $\begin{array}{l}\text { No of healthy children } \\
\text { before chromosome } \\
\text { analysis }\end{array}$ & $0.6(0-6)$ & $0.7(0-5)$ & $0.151^{*}$ \\
\hline $\begin{array}{l}\text { No of stillborn children } \\
\text { before chromosome } \\
\text { analysis }\end{array}$ & $0.04(0-1)$ & $0.04(0-1)$ & $0.793^{*}$ \\
\hline $\begin{array}{l}\text { No of diseased children } \\
\text { before chromosome } \\
\text { analysis }\end{array}$ & $0.01(0-1)$ & $0.02(0-1)$ & $0.404^{*}$ \\
\hline $\begin{array}{l}\text { No of ill or handicapped } \\
\text { children before } \\
\text { chromosome analysis }\end{array}$ & $0.05(0-2)$ & $0.04(0-1)$ & $0.462^{*}$ \\
\hline
\end{tabular}

Couples had been referred by gynaecologists from general hospitals (56\%); gynaecologists from academic hospitals (29\%); geneticists (11\%); and general practitioners, midwifes, and paediatricians (4\%). For $94 \%$ of couples the country of birth was the Netherlands.

At the time of chromosome analysis, differences existed between carrier couples and non-carrier couples (table 1). The mean maternal age was significantly lower and the mean number of miscarriages was significantly higher in carrier couples than in non-carrier couples.

The 279 structural chromosome abnormalities recorded consisted of $174(62 \%)$ reciprocal translocations, 44 (16\%) Robertsonian translocations, $3(1 \%)(\mathrm{Y} ; 22)$ translocations, $21(8 \%)$ pericentric inversions, $21(8 \%)$ paracentric inversions, $7(3 \%)$ marker chromosomes, and $9(3 \%)$ other structural chromosome abnormalities. Male and female carriers were not distributed equally: 177 (63\%) carriers were women and 102 (37\%) carriers were men.

A non-linear relation existed between maternal age and the $\log$ odds of carrier status. On the basis of the results of splines analysis, we decided to divide maternal age at second miscarriage into five categories: $<23$ years, 23-33 years, 34-36 years, 37-38 years, and $\geq 39$ years (fig 2). Figures for the other age variables were similar (data not shown). Variables with $\mathrm{P} \leq 0.2$ in univariate analysis were retained for multivariate analysis (table 2).

After multivariate logistic regression analysis, four factors influencing the probability of carrier status were retained in the final model: maternal age at second miscarriage, a history of three or more miscarriages, a history of two or more miscarriages in a brother or sister of either partner, and a history of two or more miscarriages in the parents of either partner (table 3). The sequence in which we added the subgroups did not 


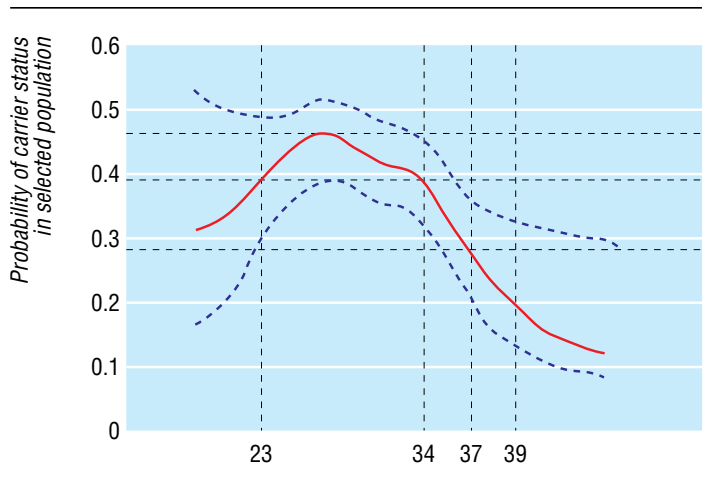

Maternal age at second miscarriage (completed years)

Fig 2 Splines analysis: probability of carrier status in different categories of maternal age at second miscarriage, with 95\% confidence intervals. Probability of carrier status is based on selected population of included couples (279 carrier couples; 428 non-carrier couples); numbers of carrier couples and non-carrier couples need to be adjusted to determine probability of carrier status in total screening population

influence the final model. Application of conditional regression analysis did not substantially alter the results.

We calculated the probability of carrier status for every combination of variables in the final model (table 4). We found a probability of carrier status of $10.2 \%$ in couples with a maternal age $<23$ years at the second miscarriage, referred after three or more miscarriages, and with a brother or sister as well as parents with a history of two or more miscarriages. At lowest risk $(0.5 \%)$ were couples with a maternal age $\geq 39$ years at the second mis-

Table 2 Factors influencing the probability of carrier status after univariate logistic regression analysis $(\mathrm{P} \leq 0.20)$

\begin{tabular}{|c|c|c|}
\hline Risk factors & Odds ratio $(95 \% \mathrm{Cl})$ & $P$ value \\
\hline \multicolumn{3}{|l|}{ Maternal age } \\
\hline $\begin{array}{l}\text { Maternal age (years) at first } \\
\text { miscarriage: }\end{array}$ & & 0.001 \\
\hline$<22$ & $4.3(1.2$ to 14.9$)$ & \\
\hline $22-31$ & 4.7 (1.6 to 13.8$)$ & \\
\hline $32-34$ & $3.5(1.1$ to 10.1$)$ & \\
\hline $35-37$ & $1.7(0.5$ to 5.8$)$ & \\
\hline$\geq 38$ & 1.0 & \\
\hline $\begin{array}{l}\text { Maternal age (years) at second } \\
\text { miscarriage: }\end{array}$ & & 0.006 \\
\hline$<23$ & 4.6 (1.3 to 16.6$)$ & \\
\hline $23-33$ & 4.0 (1.4 to 12.0$)$ & \\
\hline $34-36$ & 2.6 (0.8 to 8.1$)$ & \\
\hline $37-38$ & 1.8 (0.5 to 6.2$)$ & \\
\hline$\geq 39$ & 1.0 & \\
\hline \multicolumn{3}{|l|}{ No of miscarriages } \\
\hline $\begin{array}{l}3 \text { and } \geq 4 \text { compared with } 2 \\
\text { miscarriages: }\end{array}$ & & 0.010 \\
\hline 2 miscarriages & 1.0 & \\
\hline 3 miscarriages & $1.4(1.0$ to 2.0$)$ & \\
\hline$\geq 4$ miscarriages & 1.8 (1.2 to 2.8$)$ & \\
\hline$\geq 3$ compared with 2 miscarriages: & $1.6(1.1$ to 2.1$)$ & 0.005 \\
\hline \multicolumn{3}{|l|}{ General history } \\
\hline Exposure to radiation, either partner & 0.3 (0.1 to 1.4$)$ & 0.140 \\
\hline \multicolumn{3}{|l|}{ Obstetric history } \\
\hline$\geq 1$ ectopic pregnancies & 0.5 (0.2 to 1.2$)$ & 0.117 \\
\hline$\geq 1$ healthy children & 0.7 (0.6 to 1.0$)$ & 0.062 \\
\hline \multicolumn{3}{|l|}{ Family history } \\
\hline $\begin{array}{l}\geq 2 \text { miscarriages in a brother or } \\
\text { sister }\end{array}$ & 1.7 (1.1 to 2.6) & 0.021 \\
\hline$\geq 2$ miscarriages in parents & 1.5 (0.1 to 2.2$)$ & 0.055 \\
\hline Exposure to diethylstilbestrol & 0.5 (0.2 to 1.3$)$ & 0.144 \\
\hline
\end{tabular}

Table 3 Factors influencing probability of carrier status after multivariate logistic regression analysis $(P \leq 0.10)^{*}$

\begin{tabular}{lcc} 
Covariates & Odds ratio $\mathbf{( 9 5 \%} \mathbf{~ C l})$ & P value \\
\hline Maternal age (years) at second miscarriage: & & \\
\hline$<23$ & $6.2(1.1$ to 34.3$)$ & 0.04 \\
\hline $23-33$ & $6.1(1.3$ to 27.7$)$ & 0.02 \\
\hline $34-36$ & $3.3(0.7$ to 16.1$)$ & 0.13 \\
\hline $37-38$ & $2.3(0.4$ to 12.0$)$ & 0.33 \\
\hline$\geq 39$ & 1.0 & - \\
\hline $3 v \geq 2$ miscarriages & $1.4(1.0$ to 2.1$)$ & 0.05 \\
\hline$\geq 2$ miscarriages in a brother or & $1.9(1.1$ to 3.2$)$ & 0.02 \\
$\quad$ sister & $1.4(0.9$ to 2.2$)$ & \\
\hline$\geq 2$ miscarriages in parents & & \\
\hline${ }^{*}$ Limited to 528 couples with complete data. & &
\end{tabular}

carriage, referred after two miscarriages, and without a brother or sister or parents with a history of two or more miscarriages. Couples with a probability of carrier status below $2.2 \%$, which is the reported incidence in couples with only one miscarriage, are noted in table 4.

As the multivariate model can be used only if all variables are known, which may not always be the case, we also built a model with maternal age at second miscarriage as the only variable (table 5). According to this model, couples with a maternal age of $\geq 37$ years have a probability of carrier status below $2.2 \%$.

If chromosome analysis had been withheld from couples with a probability of carrier status below $2.2 \%$, the number of chromosome analyses would be reduced by $18 \%$ according to the multivariate model. If the model based on maternal age at the second miscarriage was applied, the reduction would be $10 \%$ (table 6).

\section{Discussion}

The results of this study show that in couples with two or more miscarriages, more factors than just the number of miscarriages influence the probability of carrier status. Low maternal age at second miscarriage, a history of three or more miscarriages, a history of two or more miscarriages in a brother or sister of either partner, and a history of two or more miscarriages in the parents of either partner all increase the probability of carrier status. We have shown that the efficiency of parental chromosome analysis could be increased by withholding the test from couples with a low probability of carrier status.

\section{Possible limitations}

The response rate among carrier couples was higher than that among non-carrier couples. This might be explained by a better understanding of the condition among carrier couples. A difference may also exist in the accuracy of data obtained by questionnaires between carrier couples and non-carrier couples. For example, carrier couples might have a better knowledge of their family history. Even though many answers were confirmed by information from medical records, the existence of such a "recall bias" cannot be ruled out entirely.

The multivariate analysis included only couples in whom all risk factors were known; 528 of the 707 couples remained for multivariate analysis. Reduction of the sample size did not, however, change the proportions of carrier and non-carrier couples.

\section{Comparison with literature}

The reported incidence of carrier status in couples with recurrent miscarriage varies between $3.6 \%$ and $5.8 \%{ }^{28}{ }^{9}$ In this study, the incidence of carrier status was relatively low at $3.2 \%$. This lower incidence might be explained by our use of more 
Table 4 Probability of carrier status in couples with two or more miscarriages, according to multivariate logistic regression model ${ }^{\star}$. Values are percentages

\begin{tabular}{|c|c|c|c|c|c|}
\hline \multirow[b]{2}{*}{ Maternal age (years) at second miscarriage } & \multirow[b]{2}{*}{$\left(\mathrm{RM}_{\mathrm{bs}}\right)$} & \multicolumn{2}{|c|}{$\left(\mathbf{R M}_{\text {parents }}\right)+$} & \multicolumn{2}{|c|}{$\left(\mathbf{R M}_{\text {parents }}\right)-$} \\
\hline & & $\geq 3$ misc & 2 misc & $\geq 3 \mathrm{misc}$ & $2 \mathrm{misc}$ \\
\hline \multirow[t]{2}{*}{$<23$} & + & 10.2 & 7.3 & 7.3 & 5.2 \\
\hline & - & 5.7 & 4.0 & 4.1 & 2.8 \\
\hline \multirow[t]{2}{*}{$23-33$} & + & 10.0 & 7.2 & 7.2 & 5.1 \\
\hline & - & 5.7 & 4.0 & 4.0 & 2.8 \\
\hline \multirow[t]{2}{*}{$34-36$} & + & 5.8 & 4.1 & 4.1 & 2.9 \\
\hline & - & 3.2 & 2.2 & 2.2 & $1.6 \dagger$ \\
\hline \multirow[t]{2}{*}{$37-38$} & + & 4.0 & 2.8 & 2.8 & $2.0 \dagger$ \\
\hline & - & 2.2 & $1.5 \dagger$ & $1.5 \dagger$ & $1.1 \dagger$ \\
\hline \multirow[t]{2}{*}{$\geq 39$} & + & $1.8 \dagger$ & $1.2 \dagger$ & $1.3 \dagger$ & $0.9 \dagger$ \\
\hline & - & $1.0 \dagger$ & $0.7 \dagger$ & $0.7 \dagger$ & $0.5 \dagger$ \\
\hline
\end{tabular}

$\mathrm{RM}_{\mathrm{bs}}=$ history of $\geq 2$ miscarriages in a brother or sister of either partner; $\mathrm{RM}_{\text {parents }}=$ history of $\geq 2$ miscarriages in parents of either partner; $\geq 3$ misc=history of $\geq 3$ miscarriages in couple; 2

misc=history of $\geq 2$ miscarriages in couple.

*Limited to 528 couples with complete data.

†Couples with probability of carrier status $<2.2 \%$

Intercept based on the total population $=-5.388$.

restrictive selection criteria for structural chromosome abnormalities. We recorded structural chromosome abnormalities according to the recommendations of the International Standing Committee on Human Cytogenetic Nomenclature, and we did not mark people with a sex chromosome aneuploidy, a chromosome polymorphism, or a low level mosaicism as carriers. ${ }^{6}$

Identifying factors that influence the probability of carrier status and calculating the probability of carrier status by using a multivariate model has not been described previously. We found that maternal age at second miscarriage was the most influential factor and that the probability of carrier status decreased at advanced maternal age. Sporadic miscarriage rates increase steeply in women in their late 30 s or older. ${ }^{8}$ The recurrence of miscarriage in this group is probably more often due to age related chromosome abnormalities, mainly trisomies, than to structural chromosome abnormalities. ${ }^{10-14}$

The couples that had chromosome analysis in the Academic Medical Hospital have been presented elsewhere. ${ }^{16}$ In this much smaller cohort, we found no significant difference in the incidence of carrier status between couples with maternal age below 36 years and couples with maternal age of 36 years and

Table 5 Probability of carrier status in couples with two or more miscarriages, according to maternal age at second miscarriage

\begin{tabular}{lc} 
Maternal age (years) at second miscarriage & Risk of carrier status (\%) \\
\hline$<23$ & 4.2 \\
\hline $23-33$ & 3.7 \\
\hline $34-36$ & 2.4 \\
\hline $37-38$ & $1.7^{*}$ \\
\hline 39 & $0.9^{*}$ \\
\hline
\end{tabular}

${ }^{*}$ Couples with probability of carrier status $<2.2 \%$.

Logistic regression analysis limited to 669 couples with complete data

Intercept based on the total population $=-4.648$. older. In the study reported here, we have clearly shown the influence of maternal age on the probability of carrier status. This can probably be explained by the larger sample size in this study.

The available literature is divided as to whether the incidence of carrier status is higher after three miscarriages than after two miscarriages. Some studies have reported no significant difference, whereas others have reported a significant increase in the incidence of carrier status after three miscarriages. ${ }^{17-19}$ Unlike our study, these studies all described series of patients without controls. We have shown an independent influence of a history of three or more miscarriages, compared with two miscarriages, on the probability of carrier status. This influence was less evident in the multivariate analysis than in the univariate analysis, because the number of miscarriages was, to some extent, correlated with the maternal age at the time of the miscarriages.

We have shown that a history of two or more miscarriages in a brother or sister of either partner or a history of two or more miscarriages in the parents of either partner influences the probability of carrier status in couples with two or more miscarriages. This finding is supported by the fact that structural chromosome abnormalities can exist within families. ${ }^{201}$

\section{Clinical implications}

Given the results of this study, the effectiveness of chromosome analysis in couples with recurrent miscarriage needs to be reconsidered. We question whether offering chromosome analysis for all couples after two or three miscarriages can still be justified. After one miscarriage, in which the reported incidence of carrier status is $2.2 \%$, chromosome analysis is not recommended. As a probability of $2.2 \%$ is apparently considered acceptable, it would seem reasonable to withhold chromosome analysis from couples with an even lower probability as well. However, $8 \%$ of the carrier couples would have remained undetected if selective chromo-

Table 6 Couples with chromosome analysis, and percentage reduction compared with current policy in period 1992-2001

\begin{tabular}{|c|c|c|c|c|c|}
\hline \multirow[b]{2}{*}{ Screening strategy } & \multicolumn{2}{|c|}{ Couples analysed ${ }^{*}$} & \multicolumn{2}{|c|}{ Reduction† } & \multirow[b]{2}{*}{ Total reduction $(\%, 95 \% \mathrm{Cl})$} \\
\hline & Carriers & Non-carriers & Carriers (\%, 95\% Cl) & Non-carriers $(\%, 95 \% \mathrm{CI})$ & \\
\hline Current policy & 382 & 11589 & - & - & - \\
\hline $\begin{array}{l}\text { Restricted policy based on four } \\
\text { predictive factors } \neq\end{array}$ & 351 & 9503 & $31(8,6$ to 11$)$ & $2086(18,17$ to 19$)$ & $2117(18,17$ to 18$)$ \\
\hline $\begin{array}{l}\text { Restricted policy based on } \\
\text { maternal age at second } \\
\text { miscarriage }\end{array}$ & 359 & 10812 & $23(6,4$ to 9$)$ & $1159(10,9$ to 10$)$ & $1182(10,9$ to 10$)$ \\
\hline
\end{tabular}

*Numbers of analysed couples adjusted to numbers of carrier couples and non-carrier couples in total population.

†Reduction if chromosome analysis withheld from couples with probability of carrier status $<2.2 \%$.

†Maternal age at second miscarriage; $\geq 3$ miscarriages; history of $\geq 2$ miscarriages in a brother or sister of either partner; history of $\geq 2$ miscarriages in parents of either partner. 


\section{What is already known on this topic}

The incidence of structural chromosome abnormalities is increased in couples with recurrent miscarriage

Currently, chromosome analysis is offered to both partners after two or three miscarriages

\section{What this paper adds}

Low maternal age at second miscarriage, a history of three or more miscarriages, a history of two or more miscarriages in a brother or sister, and a history of two or more miscarriages in the parents of either partner all increase the probability of carrier status

Selective chromosome analysis could reduce the number of chromosome analyses by $18 \%$

some analysis had been applied. The consequences of undetected carrier status is an important topic for future research.

We cannot exclude the possibility that in another clinical setting the savings might not be the same as in our study population. The referral practice might be different in other countries. Nevertheless, the results of this study are of great interest in all countries, as we have shown that the number of miscarriages is not the only factor that should be taken into account. If couples are analysed after two miscarriages, many low risk couples will be analysed as well, such as couples with maternal age at second miscarriage between 34 and 36 years, without brothers or sisters with two or more miscarriages, and without parents with two or more miscarriages. On the other hand, if couples are analysed only after three miscarriages, high risk couples will not be detected until they have a third miscarriage-for example, couples with maternal age at second miscarriage between 23 and 33 years and with brothers or sisters as well as parents with two or more miscarriages.

\section{Conclusions}

Selective chromosome analysis in couples with two or more miscarriages-that is, withholding chromosome analysis from couples with a low probability of carrier status-would result in a more appropriate referral policy, could decrease the annual number of chromosome analyses, and could therefore reduce the costs to the healthcare system.

Contributors: MG had the idea for the study and developed the study design with FvdV, NJL, MTMF, JCK, PMMB, and ACK. MTMF, MG, KBJG-S, $\mathrm{CHW}, \mathrm{KBMH}, \mathrm{RH}$, and KM collected the data. ACK selected the structural chromosome abnormalities. MTMF, JCK, and PMMB did the statistical analysis. MTMF wrote the initial draft, and all authors took part in the further preparation of the paper. MG is the guarantor.

Funding: This work was supported by ZonMW, the Netherlands Organisation for Health Research and Development (945-02-35). The sponsor did not participate in the study design, data collection, analysis, or interpretation, or in the preparation or submission of this report

Competing interests: None declared.

Ethical approval: Institutional review board approval was requested and obtained.
1 Hook EB, Healy NP, Willey AM. How much difference does chromosome banding make? Adjustments in prevalence and mutation rates of human structural cytogenetic abnormalities. Ann Hum Genet 1989;53:237-42

2 De Braekeleer M, Dao TN. Cytogenetic studies in couples experiencing repeated pregnancy losses. Hum Reprod 1990;5:519-28.

3 Royal College of Obstetricians and Gynaecologists. The investigation and treatment of couples with recurrent miscarriage. London: RCOG, 2003. (Guideline no 17.)

4 American College of Obstetricians and Gynecologists. Management of recurrent early pregnancy loss. Int J Gynaecol Obstet 2002;78:179-90.

5 Dutch Society of Obstetricians and Gynaecologists. Habitual abortion. Utrecht: Dutch Society of Obstetricians and Gynaecologists, 1999. (Guideline no 20.)

6 ISCN 1995:recommendations of the International Standing Committee on Human Cytogenetic Nomenclature. Basel: Karger, 1995.

7 Hosmer DW, Lemeshow S. Applied logistic regression. New York: John Wiley and Sons, 1989.

8 Clifford K, Rai R, Regan L. An informative protocol for the investigation of recurrent miscarriage: preliminary experience of 500 consecutive cases. Hum Reprod 1994;9: 1328-32.

9 Tharapel AT, Tharapel SA, Bannerman RM. Recurrent pregnancy losses and parental chromosome abnormalities: a review. Br J Obstet Gynaecol 1985;92:899-914.

10 Nybo-Andersen AM, Wohlfahrt J, Christens P, Olsen J, Melbye M. Maternal age and fetal loss: population based register linkage study. BMJ 2000;320:1708-12.

11 Hassold T, Chiu D. Maternal age-specific rates of numerical chromosome abnormalities with special reference to trisomy. Hum Genet 1985;70:11-7.

12 Hassold T, Hunt P. To err (meiotically) is human: the genesis of human aneuploidy. Nat Rev Genet 2001;2:280-91.

13 Cowchock FS, Gibas Z, Jackson LG. Chromosome errors as a cause of spontaneous abortion: the relative importance of maternal age and obstetric history. Fertil Steril 1993;59:1101-4.

14 Stephenson MD, Awartani KA, Robinson WP. Cytogenetic analysis of miscarriages from couples with recurrent miscarriage: a case-control study. Hum Reprod from couples

15 De la Rochebrochard E, Thonneau P. Paternal age and maternal age are risk factors for miscarriage: results of a multicentre European study. Hum Reprod 2002;17:1649-56.

16 Goddijn M,Joosten JH, Knegt AC, van der Veen F, Franssen MT, Bonsel GJ, et al. Clinical relevance of diagnosing structural chromosome abnormalities in couples with repeated miscarriage. Hum Reprod 2004;19:1013-7.

17 Fryns JP, van Buggenhout G. Structural chromosome rearrangements in couples with recurrent fetal wastage. Eur J Obstet Gynecol Reprod Biol 1998;81:171-6.

18 Portnoi MF, Joye N, van den Akker J, Morlier G, Taillemite JL. Karyotypes of 1142 couples with recurrent abortion wastage. Obstet Gynecol 1988:72:31-4

19 Bourrouillou G, Colombies P, Dastugue N. Chromosome studies in 2136 couples with spontaneous abortions. Hum Genet 1986;74:399-401.

20 Smith A, Gaha TJ. Data on families of chromosome translocation carriers ascertained because of habitual spontaneous abortion. Aust N ZJ Obstet Gynaecol 1990;30:57-62.

21 Sachs ES, Jahoda GJ, van Hemel JO, Hoogeboom AJM, Sandkuyl LA. Chromosome studies of 500 couples with two or more abortions. Obstet Gynecol 1985;65:375-8.

(Accepted 23 May 2005)

doi 10.1136/bmj.38498.669595.8F

Centre for Reproductive Medicine, Department of Obstetrics and Gynaecology, Academic Medical Centre, University of Amsterdam, PO Box 22660, 1100 DD Academic Medical Centre,
Amsterdam, Netherlands

Maureen T M Franssen researcher

Fulco van der Veen professor

Mariette Goddijn gynaecologist

Department of Clinical Genetics, Academic Medical Centre, University of Amsterdam

Nico J Leschot professor

Alida C Knegt clinical cytogeneticist

Department of Clinical Epidemiology and Biostatistics, Academic Medical Centre, University of Amsterdam

Johanna C Korevaar epidemiologist

Patrick M M Bossuyt professor

Department of Clinical Genetics, University Hospital Groningen, Groningen Klasien B J Gerssen-Schoorl clinical cytogeneticist

Department of Clinical Genetics, Erasmus Medical Centre, Rotterdam Cokkie H Wouters clinical cytogeneticist

Department of Clinical Genetics, Leiden University Medical Centre, Leiden Kerstin B M Hansson clinical cytogeneticist

Department of Clinical Genetics, University Medical Centre Utrecht, Utrecht Ron Hochstenbach clinical cytogeneticist

Department of Clinical Genetics, VU Medical Centre, University of Amsterdam Kamlesh Madan clinical cytogeneticist

Correspondence to: M T M Franssen maureen.franssen@planet.nl 